\title{
Unified natural mortality estimation for teleosts and elasmobranchs
}

\author{
Manuel Dureuil ${ }^{1,2, *}$, William H. Aeberhard ${ }^{3}$, Kirsti A. Burnett ${ }^{2}$, Robert E. Hueter ${ }^{4}$, \\ John P. Tyminski ${ }^{4}$, Boris Worm ${ }^{1}$ \\ ${ }^{1}$ Department of Biology, Dalhousie University, Halifax, NS B3H 4R2, Canada \\ ${ }^{2}$ Sharks of the Atlantic Research and Conservation Centre, Dartmouth, NS B2Y 1K2, Canada \\ ${ }^{3}$ Swiss Data Science Center, ETH Zurich, 8006 Zurich, Switzerland \\ ${ }^{4}$ Center for Shark Research, Mote Marine Laboratory, Sarasota, FL 34236, USA
}

\begin{abstract}
Natural mortality, $M$, is a key parameter for the assessment and management of living resources but is difficult to observe directly. Therefore, $M$ is often estimated indirectly from life history traits, and it is typically assumed to be invariant over size, age, and time. Such indirect estimators are particularly relevant for data-poor species, including many elasmobranchs (sharks, skates, and rays). However, as commonly used estimators were developed largely with teleost (bony fish) data, their performance for elasmobranchs is currently unknown. Here, we show that the relationship between observed maximum age, $t_{\max }$ and mean adult $M$ is not significantly different between teleosts $(n=105)$ and elasmobranchs $(n=15)$. Furthermore, data on 16 teleosts and 2 elasmobranchs suggest that juvenile $M$ can be estimated from adult $M$ when juvenile $M$ is inversely proportional to body length and when a reference length can be provided. We introduce this reference length as the length at the age after which $M$ is assumed to be constant and demonstrate how it can be estimated using the von Bertalanffy growth function and the proportion surviving to $t_{\max }$ which is shown to be approximately $1-2 \%$. The data utilized here also suggest that if $t_{\max }$ is unknown it can be estimated from growth information by assuming that $99 \%$ of the asymptotic maximum length is reached at $t_{\max }$. Based on these life history parameters, the same indirect $M$ estimators can be utilized for teleosts and elasmobranchs, which may contribute to more reliable assessments of data-poor species.
\end{abstract}

KEY WORDS: Adult survival $\cdot$ Juvenile survival $\cdot$ Natural mortality $\cdot$ Life expectancy $\cdot$ Longevity · Growth · von Bertalanffy · Shark

\section{INTRODUCTION}

Globally, many overexploited marine species are lacking scientific assessments, which hampers sustainable use and effective conservation (Dulvy et al. 2014, Costello et al. 2016, Simpfendorfer \& Dulvy 2017). This lack of information is also reflected by the proportion of species listed as Data Deficient on the IUCN's Red List of Threatened Species for marine taxonomic groups that are of major conservation concern. Within these groups, elasmobranchs (sharks,

\footnotetext{
*Corresponding author: manueldureuil@gmail.com
}

skates, and rays) have the highest proportion of data deficiency, at $47 \%$ (Dulvy et al. 2014; www.iucn redlist.org). In such situations, one solution to gain knowledge critical for species' assessments is to investigate whether common ecological principles across taxa allow for information to be shared between data-rich and data-poor species (Kindsvater et al. 2018). This is common practice, for example, when estimating the natural mortality rate, M (Pauly 1980, Hoenig et al. 2016). M is a highly influential parameter in many stock assessments and usually expressed

() The authors 2021. Open Access under Creative Commons by Attribution Licence. Use, distribution and reproduction are unrestricted. Authors and original publication must be credited. 
as an instantaneous rate of decline within an exponential decay model:

$$
N_{t}=N_{0} \times \mathrm{e}^{-[(M+F) \times t]}
$$

where $N_{t}$ is the number of individuals at time $t$ (years), $N_{0}$ is the initial number of individuals, $M$ is the instantaneous rate of natural mortality, and $F$ is the instantaneous rate of fishing mortality (both $M$ and $F$ given in $\mathrm{yr}^{-1}$ ), with the sum of $M$ and $F$ adding up to the total mortality rate, $Z$. $M$ is often required in the estimation of many important parameters, such as the prediction of catch and abundance (Haddon 2011) and the intrinsic rate of population increase (Simpfendorfer 2005, Pardo et al. 2018) or rebound potentials (Smith et al. 1998). In particular, $M$ affects key reference parameters in fisheries, such as optimal exploitation rates, resilience, and productivity (Maunder \& Wong 2011). For example, $M$ has been widely used in fisheries management as a proxy for the level of $F$ that produces maximum sustainable yield (Gulland 1971, Zhou et al. 2012). Furthermore, inaccurate rates of $M$ can influence predicted stock size, especially when it is overestimated (Sims 1984, Johnson et al. 2015). Higher rates of $M$ translate to higher estimated stock sizes (Cheilari \& Rätz 2009) and reference points (Cheilari \& Rätz 2009, Maunder \& Wong 2011), and underestimated rates of $F$ (Cheilari \& Rätz 2009). Consequently, incorrect $M$ estimates can result in biased estimates of stock status (Clark 1999), increasing the risk of mismanagement.

Ideally, $M$ is estimated empirically via direct methods, i.e. from mark-recapture tagging data (Hoenig et al. 1998), telemetry data (Heupel \& Simpfendorfer 2002, Knip et al. 2012), catch curves used to estimate $Z$ in unexploited, newly exploited, or very lightly exploited populations (Simpfendorfer 1999), or by extrapolating $M$ from $Z$ and fishing effort (Pauly 1984). In very data-rich situations, $M$ can also be estimated within stock assessments (Lee et al. 2011). However, these methods have limited applicability for datapoor groups, including many elasmobranchs.

Alternatively, indirect methods to estimate $M$ have been developed, which utilize a relationship between the $M$ and other life history traits. For example, Hoenig (1983) showed that in an unexploited population with no $F$, Eq. (1) can be reformulated to yield the following linear predictive equation:

$$
\log _{\mathrm{e}}(M)=\beta_{0}+\beta_{1} \times \log _{\mathrm{e}}\left(t_{\max }\right)
$$

where $\beta_{0}$ and $\beta_{1}$ are constants (the intercept and slope) to be estimated from a linear regression model, and $t_{\max }$ is the maximum age observed. Hence, a relationship can be developed empirically across species for which directly estimated rates of $M$ (e.g. from catch curves in unexploited populations) and observed $t_{\max }$ are available. This relationship can then be used to obtain an estimate of $M$ indirectly in species where $M$ is unknown and cannot be estimated via direct methods, but for which $t_{\max }$ or any other life history parameter suitable to estimate $M$, is known. Many of these indirect $M$ estimators have been developed (see Kenchington 2014 for a review) and generally require information on $t_{\max }$ (Hoenig 1983, Then et al. 2015), age at maturity $\left(t_{m}\right)$ (Jensen 1996), or growth (Pauly 1980, Jensen 1996, Then et al. 2015).

Additionally, many indirect methods typically assume that $M$ is a constant that is independent of age, size, and time, which is also a common assumption in fisheries assessments (Vetter 1988). While age and size independence might well be a valid assumption during the adult phase (Brodziak et al. 2011, Deroba \& Schueller 2013, Johnson et al. 2015), it may not hold for juveniles, which can experience substantially higher mortality rates than adults in both teleosts (bony fish) and elasmobranchs (Peterson \& Wroblewski 1984, Chen \& Watanabe 1989, Lorenzen 1996, 2000, Gruber et al. 2001, Gislason et al. 2010, Heupel \& Simpfendorfer 2011). In response, indirect methods relating life history parameters to age- and sizedependent $M$ rates have been developed (e.g. Peterson \& Wroblewski 1984, Chen \& Watanabe 1989, Lorenzen 1996, 2000, Gislason et al. 2010).

However, to date, both invariant and variant estimators for $M$ have almost exclusively utilized information from teleosts, although the development of taxon-specific alternatives has been suggested (Kenchington 2014). In contrast to many teleosts, elasmobranchs are more generally characterized by low $M$ rates, slow growth, late maturity, low fecundity, extended reproductive cycles, and longer lifespans (Hoenig \& Gruber 1990, Camhi et al. 1998, Cortés 2000, Dulvy et al. 2014), similar to marine mammals (Smith et al. 1998). Therefore, it has been proposed that $M$ estimators derived from cetacean (whales, dolphins, and porpoises) data can be used for elasmobranchs (Cortés 1998, Simpfendorfer et al. 2005), an approach that has been applied to several species (Cortés 1998, McAuley et al. 2007, Heupel \& Simpfendorfer 2011, Hisano et al. 2011, Liu et al. 2015, Lessa et al. 2016, Yokoi et al. 2017, Queiroz et al. 2019). Yet the lack of adequate data has prevented detailed investigation of the performance of these indirect $M$ estimators for elasmobranchs (Kenchington 2014).

Here, updated adult and juvenile databases for marine elasmobranchs and teleosts, with rates of $M$ estimated from direct methods and associated life 
history information, were assembled. Original sources were carefully checked before extracting the direct $M$ estimates. In addition, newly collected or previously unconsidered data were analyzed for elasmobranchs, combined with an extensive literature review, to obtain a larger sample of directly estimated $M$ rates for this group. On this basis, an empirically updated $M$ estimator was developed to investigate if taxon-specific estimators are required for teleosts and elasmobranchs. Furthermore, various indirect methods which estimate rates of $M$ from other life history parameters were compared to the direct estimates from the updated databases, for both juveniles and adults. Overall, our analyses aim to aid improved assessments and scientific management of data-poor species.

\section{MATERIALS AND METHODS}

\subsection{Data}

Two updated $M$ databases were developed: one for adult elasmobranchs and teleosts (see Table S1 in Supplement 1 at www.int-res.com/articles/suppl/m667 p113_supp1.xlsx), and one for juveniles (Table S2). These databases contain direct estimates of $M$ as well as associated life history information required by many indirect estimators. All parameters were standardized to the same units. Rates are given in $\mathrm{yr}^{-1}$, ages are given in years, and length is given in $\mathrm{cm}$ total length (TL) throughout. When TL was not available, it was estimated from length-length relationships using the provided length type.

\subsubsection{Adult $M$ data}

Adult $M$ is defined here as a constant average annual instantaneous mortality rate of adult individuals. For teleosts, direct estimates of $M$ were obtained from peer-reviewed literature by carefully checking and consulting the original sources utilized in a recently published extensive database (Then et al. 2015). The following selection criteria were applied: (1) only $M$ values from wild populations derived via direct methods in the original source, and from marine species for which the majority of data used to estimate $M$ came from adults, were considered; furthermore, estimates were excluded that (2) were unreliable (e.g. $Z$ was smaller than $M_{i} M$ was based on expert opinion; $M$ was derived from mark-recapture methods that did not consider immigration and emigra- tion, tag loss, reporting rate, or tagging mortality); (3) were considered unreliable or questionable by the authors in the original study; (4) were based on estimates of $Z$, and assumed $Z=M$, but the level of exploitation was unknown or the population was exploited and could not be considered very lightly exploited; and/or (5) had no estimate of corresponding $t_{\max }$ available. If the authors of the present study were aware of revised $M$ estimates based on more and/or updated data, those estimates were used. Excluded references along with an explanation are provided in Table S3. Sex-specific $M$ estimates were preferred over combined estimates, given that the other life history parameters were also available for each sex. In the absence of sex-specific information, the average $M$ across both sexes was taken. If several direct methods were applied or the study gave several direct $M$ estimates and the authors did not specifically exclude the validity of a method or estimate, the average across methods or estimates was calculated. We also used the average when a study gave several $M$ estimates from a single unexploited population but from different areas.

For elasmobranchs, an extensive literature search including grey literature (such as government reports) was conducted to gather any additional information not yet included in previous work. Direct $M$ estimates for elasmobranchs were also obtained from newly collected data and published data not previously considered to estimate $M$. Published estimates for which updated information was available were re-analyzed. When sample size was sufficient, $M$ was estimated for males and females independently. One value of elasmobranch $M$ reported in Knip et al. (2012) that was extremely outlying was excluded from the analysis (see Fig. S1 in Supplement 2 at www. int-res.com/articles/suppl/m667p113_supp2.pdf).

\subsubsection{Juvenile $M$ data}

Juvenile $M$ is defined here as an annual instantaneous mortality rate estimated at a certain length, age, or weight representative for a juvenile individual. Direct estimates of juvenile $M$ were obtained from an extensive literature search, applying the same criteria as described above. In addition, only directly estimated mortality rates at a juvenile length, weight, or age and estimated per $1 \mathrm{yr}$ (with units $\mathrm{yr}^{-1}$ ) were included to avoid extrapolation. Juvenile $M$ estimates that were lower overall than adult $M$ estimates were not considered, because all tested methods assume a declining rate of $M$ with age, length, or 
weight. Generally, the underlying samples consisted of juvenile individuals with various length or age classes, and therefore juvenile $M$ refers here to the instantaneous $M$ at a mean length. If not provided in the original source, the mean length at juvenile $M$ was calculated as the mean between the minimum and maximum length in the sample. If an age range was given instead, then length was calculated using the von Bertalanffy growth function (von Bertalanffy 1938):

$$
L_{t}=L_{\infty}-\left(L_{\infty}-L_{0}\right) \mathrm{e}^{-k t}=L_{\infty} \times\left(1-\mathrm{e}^{-k\left(t-t_{0}\right)}\right)
$$

where $L_{t}$ is the length at age $t_{1} L_{0}$ is the length at age $0, L_{\infty}$ is the asymptotic length, $k$ is a curve parameter describing how fast $L_{\infty}$ is approached, and $t_{0}$ is the theoretical age at zero length. $L_{0}$ can be obtained from $t_{0}$, as:

$$
L_{0}=L_{\infty} \times\left(1-\mathrm{e}^{-k \times-t_{0}}\right)
$$

\subsubsection{Life history data}

Life history information on observed $t_{\max }$, von Bertalanffy growth parameters, and $t_{m}$ were extracted from the same original study that estimated $M$ values, if possible, or obtained from a literature search. Only information from the same population was considered, and similar time periods and locations were preferred. If $t_{m}$ was not available, but length at maturity $\left(L_{m}\right)$ and growth information were available, then $t_{m}$ was calculated using a rearranged von Bertalanffy growth function:

$$
t=\frac{\log _{\mathrm{e}} \frac{\left(L_{\infty}-L_{0}\right)}{\left(L_{\infty}-L_{t}\right)}}{k}=-\log _{\mathrm{e}}\left(1-\frac{L_{t}}{L_{\infty}}\right) / k+t_{0}
$$

where $t=t_{m}$ and $L_{t}=L_{m}$. Likewise, if $L_{m}$ was not available but $t_{m}$ and growth were available, then $L_{m}$ was estimated using the von Bertalanffy growth function (Eq. 3). For some bony fish where larvae are exceedingly small at birth, length at birth was assumed to be 0 if $t_{0}$ was not provided. The mean environmental temperature inhabited by the species, $T$ $\left({ }^{\circ} \mathrm{C}\right)$, was mainly taken from Then et al. (2015) or FishBase (Froese \& Pauly 2019), if not indicated otherwise in Table S1. Weight ( $W_{i}$ in $g$ ) was calculated from the corresponding length class $(L)$ using lengthweight relationships (Froese 2006). If the direct $M$ estimate was only available for combined sexes, certain areas, or time periods, then the average of the life history parameters was taken across the corresponding sexes, areas, or time periods, if possible.

\subsection{Adult $M$ estimator}

In total, 4 updated indirect adult $M$ estimators were developed:

(1) Given the log-linear relationship between $t_{\max }$ and $M$ (Eq. 2), a linear regression analysis of direct $M$ estimates versus observed $t_{\max }$ from the adult $M$ database was developed to estimate the parameters $\beta_{0}$ and $\beta_{1}$. This estimator is hereafter referred to as Estimator Tmax. The response variable, $M$, and the covariate, $t_{\text {max }}$, were $\log _{\mathrm{e}}$ transformed.

(2) Estimator Tmax requires an input of observed $t_{\max }$. In the absence of an observed value, $t_{\max }$ might be estimated from the von Bertalanffy growth function:

$$
\hat{t}_{\text {max }}=\frac{1}{k} \times \log _{\mathrm{e}}\left\{\left(L_{\infty}-L_{0}\right) /\left[(1-X) \times L_{\infty}\right]\right\}
$$

where $X$ is the proportion of $L_{\infty}$ reached at $t_{\max }$. Commonly, $X$ is assumed to be 0.95 (Taylor 1958, Ricker 1979), and the estimator with an estimated $t_{\text {max }}$ using $X=0.95$ is hereafter referred to as Estimator Linf95.

(3) The proportion of $L_{\infty}$ reached at $t_{\max }$ was also calculated using all available information on growth and observed $t_{\max }$ in the adult $M$ database via:

$$
X=\left[L_{\infty}-\left(L_{\infty}-L_{0}\right) \times \mathrm{e}^{\left(-k \times t_{\max }\right)}\right] / L_{\infty}
$$

The estimated $t_{\max }$ with $X$ as the median across all species was then used as input in the Estimator Tmax. This estimator is hereafter referred to as Estimator Linf.

(4) The adult $M$ can also be estimated from the proportion of the cohort, $P$, that remains alive at $t_{\text {max }}$ :

$$
M=\frac{-\log _{\mathrm{e}}(P)}{t_{\max }}
$$

$P$ has often been assigned an arbitrary value of 0.01 or 0.05 , while empirical data suggest a value of 0.015 (Hewitt \& Hoenig 2005). Here, the $P$ value was empirically updated. First, each single $P$ value was calculated from the corresponding directly estimated $M$ rate and the observed $t_{\max }$ in the adult $M$ database, $P=\mathrm{e}^{\left(-M \times t_{\max }\right)}$. Then, the median across all individual $P$ values was utilized in Eq. (8). This estimator is referred to as Estimator $P$.

\subsection{Juvenile $M$ estimator}

An updated indirect juvenile $M$ estimator was developed based on Lorenzen (2000), who suggested that $M$ scales inversely proportional with body length:

$$
M_{L}=M_{r} \frac{L_{r}}{L}
$$


This estimator needs a constant $M$ rate $\left(M_{r}\right)$ at a specific reference length $\left(L_{r}\right)$ as input, along with $L_{\infty}$ (Beyer et al. 1999) and $L_{m}$ (Brodziak et al. 2011), both proposed as reference lengths in the past. Here, this estimator was updated using the predicted constant adult $M$ rate from the Estimator Tmax as input for $M_{r}$, and a newly defined reference length, the length at the age after which $M$ can be assumed constant: $L_{t a}$. This length was derived as follows: the adult constant $M$ rate is related to the average life expectancy, $E$, in the form:

$$
M=\frac{1}{E}
$$

Now $E$ can be defined as the average life expectancy after the age at which $M$ is assumed constant, $t_{a}$ :

$$
E=\frac{t_{\max }-t_{a}}{2}
$$

It can be further defined that $x$ is the proportion of $t_{\max }$ at which $M$ is assumed constant:

$$
E=\frac{t_{\max }-\left(x \times t_{\max }\right)}{2}
$$

and therefore:

$$
M=\frac{2}{t_{\max }-\left(x \times t_{\max }\right)}=\frac{2}{t_{\max } \times(1-x)}=\frac{\frac{2}{(1-x)}}{t_{\max }}
$$

This implies that $M$ can be estimated from a constant divided by $t_{\max }$, which is equivalent to the definition in Eq. (8):

$$
M=\frac{\frac{2}{(1-x)}}{t_{\max }}=\frac{-\log _{\mathrm{e}}(P)}{t_{\max }}
$$

From this, it follows that:

$$
\frac{2}{(1-x)}=-\log _{\mathrm{e}}(P)
$$

which can be solved for $x$ :

and hence:

$$
x=\frac{2}{\log _{\mathrm{e}}(P)}+1
$$

$$
t_{a}=\left(\frac{2}{\log _{\mathrm{e}}(P)}+1\right) \times t_{\max }
$$

The same empirically derived $P$ as in Estimator $P$ was used here, i.e. the median across all calculated proportions based on the information in the adult $M$ database. Finally, $L_{t a}$ was obtained from $t_{a}$ via the von Bertalanffy growth function. This estimator, with $L_{t a}$ as a reference length, is referred to as Estimator Lta.

\subsection{Evaluation of estimators}

The linear regression assumptions underlying the indirect adult $M$ estimator (Estimator Tmax) were evaluated using several well-established methods. Fitted values were plotted against the residuals to check for homogeneity of variances. Then et al. (2015) implied that the independence of observations assumption of linear regression might be violated when $M$ is estimated for the same species with information from different locations or sexes. Therefore, the residuals were tested on auto-correlation graphically via the auto-correlation-function (acf) plot in $\mathrm{R}$ version 3.5.2 (R Core Team 2018). For this purpose, the data for all investigated populations were ordered for taxonomy, species, sex, and location. In addition, a sensitivity analysis was performed. First, it was determined if a combined taxa (elasmobranch and teleost) estimator is valid by applying 3 approaches: (1) testing if taxon (elasmobranch or teleost) as an additional covariate is significant and if the model improves in terms of having a lower Akaike information criterion (AIC) value; (2) comparing the Estimator Tmax parameters for combined taxa with the parameters from linear regression models for each taxon; and (3) comparing the Estimator Tmax parameters with the parameters from a linear regression model that only utilized information from species where $t_{\max } \geq 3 \mathrm{yr}$, because elasmobranchs attain higher maximum ages than teleosts (Nielsen et al. 2016). A $t_{\max }$ of $3 \mathrm{yr}$ was selected because $3 \mathrm{yr}$ is among the lowest reported values of $t_{\max }$ in elasmobranchs (Cailliet \& Goldman 2004). Second, it was determined if the use of (ordinary least squares) linear regression is valid by comparing the Estimator Tmax parameters with the parameters obtained from other linear regression techniques: (1) robust linear regression to investigate if a few observations have a high influence through the assessment of robustness weights computed in the fitting process, using the command 'rlm' in the R package 'MASS' (Venables \& Ripley 2002); (2) major axis regression (a special case of orthogonal regression or errors-in-variables regression), which minimizes a different loss function than the sum of squared residuals to take into account that the covariate $t_{\max }$ is technically also measured with error (i.e. also random), using the R package 'lmodel2' (Legendre 2018). Furthermore, to evaluate indirect $M$ estimates obtained from Estimator Tmax against $M$ estimates obtained from direct methods, 10-fold cross validation was used to obtain an out-of-sample prediction error (Then et al. 2015, Hoenig et al. 2016) via the 'DAAG' package (Maindonald \& Braun 2015). Here, the data were split into 10 random subsets; each subset was then excluded at a time so the remaining data points were used to refit the model to predict the excluded observations. 
Hoenig et al. (2016) and Then et al. (2015) also suggest that the hierarchical nature of the data has to be taken into consideration, as this can violate assumptions of independence. We considered mixed-effect models with taxonomic order as a random intercept/slope to check for possible within-order dependence. The results were similar and not significantly different from ordinary regression, yet the small number of observations for many orders ( 7 out of 15 orders with only 1 observation) does not allow fitting such models with confidence. We therefore excluded random effect models from this analysis.

All updated indirect $M$ estimators (Estimator Tmax, Estimator P, Estimator Linf95 Estimator Linf, and Estimator Lta) were compared in their performance against previously published indirect $M$ estimators. This comparison was done by evaluating the accuracy and precision of the indirect estimators in predicting the direct $M$ estimates in the adult or juvenile $M$ database, respectively.

For adult $M, 10$ more commonly applied indirect adult $M$ estimators were used for comparison (Table 1). For juvenile $M$, comparisons were done using 7 more commonly applied age-, size-, or weight-dependent indirect $M$ estimators (Table 2). For estimators using weight instead of length, the mean weight (in g) was calculated from mean length using length-weight relationships (Froese 2006). For estimators using age instead of length, mean age was obtained from mean length using the von Bertalanffy growth function (Eq. 5). To evaluate the performance of the different estimators, recommendations of Walther \& Moore (2005) were followed, and scaled measures were used. First, the relative error (in \%) was calculated:

$$
\text { Relative error }=\frac{\widehat{M_{i}}-M}{M} \times 100
$$

where $M$ is the reference parameter, i.e. the $M$ value obtained from the direct methods in the $M$ databases, and $\widehat{M}$ is the corresponding $i^{\text {th }}$ estimate from each of the investigated estimators. Boxplots were used to show the median and variation in the relative error for each estimator. Then, to evaluate the performance based on accuracy and precision, 2 additional measures were calculated, the scaled mean absolute error, SMAE:

$$
\mathrm{SMAE}=\operatorname{mean}\left(\left|\frac{\widehat{M}_{i}-M}{M}\right|\right)
$$

and the scaled median absolute deviation, SMAD, to also evaluate a measure more robust against outliers:

$$
\mathrm{SMAD}=\operatorname{median}\left(\left|\frac{\widehat{M}_{i}-M}{M}\right|\right)
$$

Smaller values for the relative error, SMAE, and SMAD indicated better performance. Note that SMAE and SMAD are strictly positive values, and only the relative error can be utilized to evaluate the potential direction of bias (overestimation or underestimation) of an estimator. 
Table 2. Indirect estimators of juvenile natural mortality $\left(M_{i} \mathrm{yr}^{-1}\right)$, at length, age, or weight estimators based on von Bertalanffy growth parameters $k\left(\mathrm{yr}^{-1}\right)$ and $L_{\infty}(\mathrm{cm})$, weight ( $\left.W_{i} g\right)$, length $\left(L_{i} \mathrm{~cm}\right)$, age $\left(t_{i}\right.$ years $)$, and age at which senescence (the increase of mortality at old ages) commences ( $t_{s i}$ years). The method of Lorenzen (2000), LorL, requires a constant reference $M$ rate $\left(M_{r}\right)$ at a reference length. Here, adult $M$ estimated from Estimator Tmax was utilized as $M_{r}$ and 3 reference lengths were tested: the length after which $M$ is assumed constant $\left(L_{t a}\right)$, the length at maturity $\left(L_{m}\right)$ (Brodziak et al. 2011) and $L_{\infty}$ (Beyer et al. 1999). The method of Peterson \& Wroblewski (1984), PW, was derived from dry weights (in $\mathrm{g}$ ); dry weight was assumed to be $20 \%$ of wet weight (Cortés 2002)

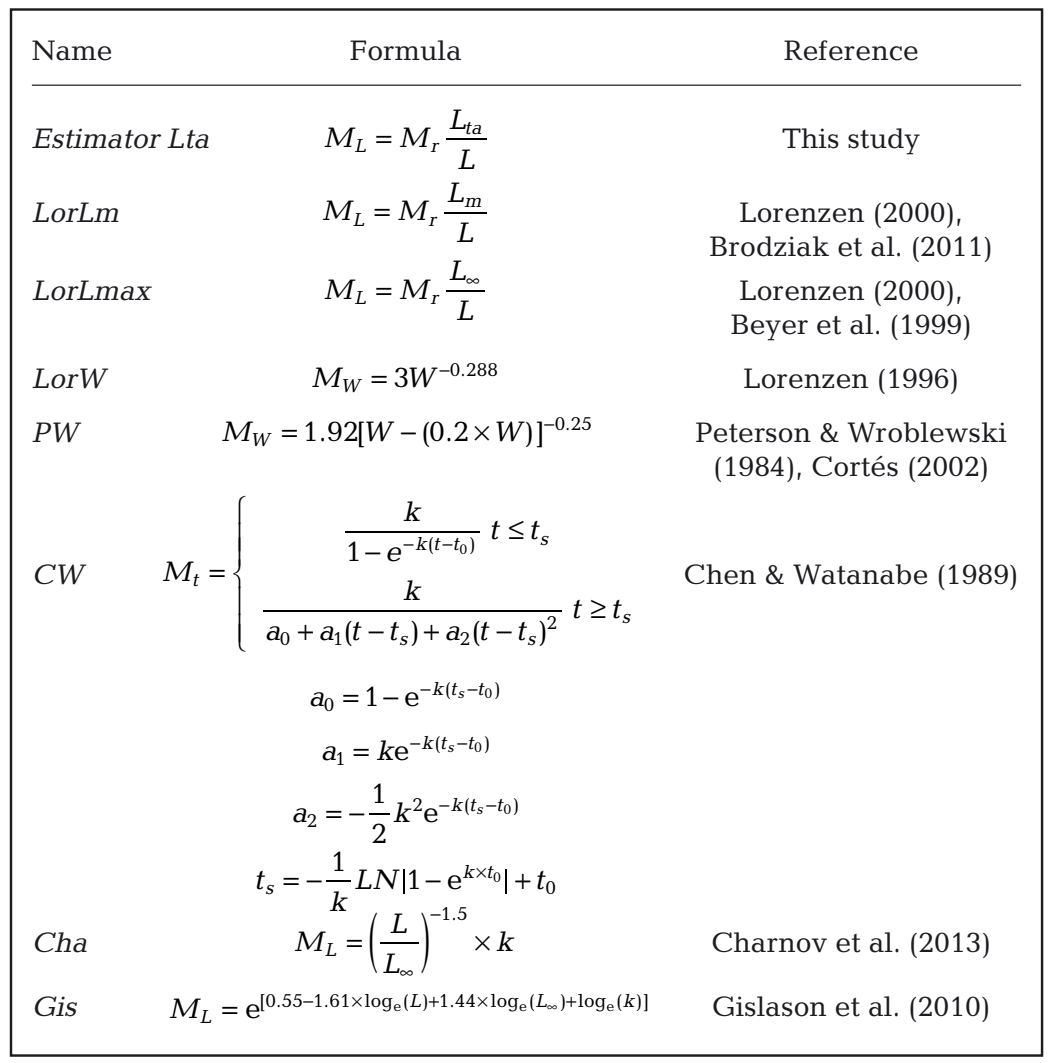

Each estimator was tested on the maximum number of observations, whether all life history information was complete for a particular observation or not. This process can introduce bias and prevent a fair comparison in which outlier species (or populations) or non-randomness would not affect all estimators the same (Hoenig et al. 2016). Therefore, all estimators were additionally tested on a common database, where only direct $M$ estimates were included for which all other life history information that are required by any of the estimators were available. Furthermore, the residuals (direct $M$ from databases minus predicted $M$ from estimator) were plotted against the predicted $M$ from the indirect estimators to identify estimators with better behaving error structure (Then et al. 2015).

\section{RESULTS}

\subsection{Adult $M$}

In total, 120 direct adult $M$ estimates for marine fish from 70 different sources were utilized for the adult $M$ database. Direct $M$ estimates came from 105 teleosts and 15 elasmobranchs from 15 taxonomic orders within 39 families, comprising 77 and 12 different teleost and elasmobranch species, respectively. The direct $M$ estimates came primarily from catch curves, i.e. applying a linear regression to the $\log _{e}$-transformed Eq. (1) in unexploited or lightly exploited populations, so that $M$ approximates $Z$. Direct $M$ estimates ranged from 7.92 to $0.014 \mathrm{yr}^{-1} ; t_{\max }$ range was $0.73-$ $131.5 \mathrm{yr}$ in teleosts and 5.7-73 yr in elasmobranchs. $L_{\infty}$ range was $4.72-$ $280 \mathrm{~cm}$ and $k$ range was 2.555$0.034 \mathrm{yr}^{-1}$. Of the 120 direct $M$ and $t_{\max }$ estimates, 118 estimates also had corresponding von Bertalanffy growth parameters available, and 86 estimates also had $t_{m}$ data available.

Based on the updated adult $M$ database, the Estimator Tmax is given by:

$$
M=\mathrm{e}^{\left[1.551-1.066 \times \log _{\mathrm{e}}\left(t_{\max }\right)\right]}
$$

This estimator had a 10-fold cross validation prediction error of 0.13 . The linear relationship between $M\left(\log _{\mathrm{e}}\right.$ $\mathrm{yr}^{-1}$ ) and $t_{\max }\left(\log _{\mathrm{e}} \mathrm{yr}\right)$ was highly significant $\left(\mathrm{R}^{2}=0.92, \mathrm{p}<0.0001\right.$; Table 3$)$. The predictions from the Estimator Tmax showed a good fit to both elasmobranch and teleost data and when compared to existing $t_{\max }$-based indirect estimators (Fig. 1). There was no significant difference when 'taxa' were added as an additional covariate ( $\mathrm{p}=$ 0.74 ) nor did the model improve with the same coefficient of variation $\left(\mathrm{R}^{2}=0.92\right)$ and a slightly higher AIC (Table 3). Furthermore, the linear regression for each taxon individually and the linear regression based on comparable $t_{\max }$ only showed similar parameter estimates and overlapping confidence intervals when compared to Estimator Tmax (Table 4). Likewise, the parameter estimates were very similar across linear regression techniques and all were within the confidence intervals of the Estimator Tmax estimates (Table 4). 
Table 3. Relationship of natural mortality $(M)$ and maximum age $\left(t_{\max }\right)$ between elasmobranchs and teleosts. Shown are the estimated coefficients from

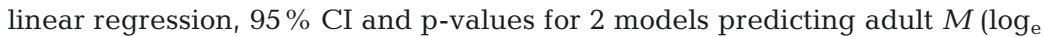
$\left.\mathrm{yr}^{-1}\right)$. The first model is the Estimator Tmax with only $t_{\max }\left(\log _{\mathrm{e}} \mathrm{yr}\right)$ as a covariate (bold). The second model has an additional covariate, taxa (elasmobranch or teleost). Both models had a coefficient of variation, $\mathrm{R}^{2}$, of 0.92 . The model with only $t_{\max }$ as a covariate had a slightly lower Akaike information criterion (AIC) of 100 compared to 102 for the model with $t_{\max }$ and taxa as covariates

\begin{tabular}{|c|c|c|c|c|}
\hline Model & & $\beta$ & $95 \% \mathrm{CI}$ & $\mathrm{p}$ \\
\hline $\log _{\mathrm{e}}(M)=\beta_{0}+\beta_{1} \times \log _{\mathrm{e}}\left(t_{\max }\right)$ & $\begin{array}{l}\text { Intercept } \\
\log _{\mathrm{e}} t_{\max }\end{array}$ & $\begin{array}{r}1.551 \\
-1.066\end{array}$ & $\begin{array}{c}1.39,1.71 \\
-1.12,-1.01\end{array}$ & $\begin{array}{l}<0.001 \\
<0.001\end{array}$ \\
\hline $\begin{aligned} \log _{\mathrm{e}}(M)= & \beta_{0}+\beta_{1} \times \log _{\mathrm{e}}\left(t_{\max }\right) \\
& +\beta_{2} \times \text { taxa }\end{aligned}$ & $\begin{array}{l}\text { Intercept } \\
\log _{\mathrm{e}} t_{\max } \\
\text { Taxa }\end{array}$ & $\begin{array}{r}1.519 \\
-1.065 \\
0.033\end{array}$ & $\begin{array}{c}1.27,1.77 \\
-1.12,-1.01 \\
-0.17,0.23\end{array}$ & $\begin{array}{c}<0.001 \\
<0.001 \\
0.74\end{array}$ \\
\hline
\end{tabular}

The variances of the Estimator Tmax predictions were homogeneous (Fig. S2), the residuals had an approximate normal distribution (Fig. S3; Shapiro-Wilk $\mathrm{p}=0.05$; Kolmogorov-Smirnov $\mathrm{p}<$ 0.0001), and there was no residual auto-correlation (Fig. S4). This suggests that the use of the ordinary linear regression model was appropriate.

In the absence of an observed value for $t_{\max }$, it may be estimated using the von Bertalanffy growth function. The percentage of the $L_{\infty}$ reached at maximum age $X$ was set at 0.95 for the Esti-

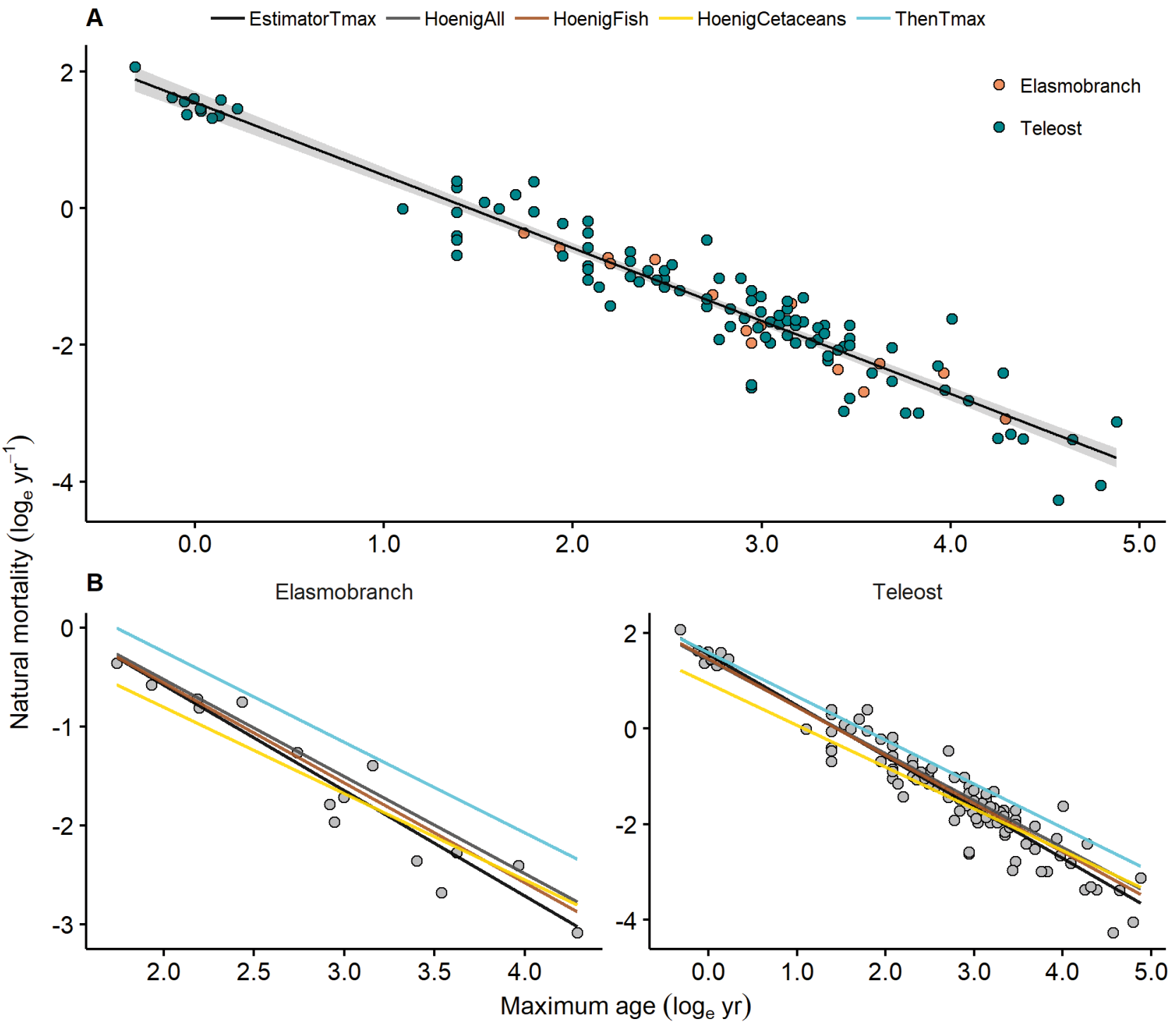

Fig. 1. Relationships between natural mortality $(M)$ and maximum age $\left(t_{\max }\right)$ in marine fish. (A) Black line: predicted relationship (Estimator Tmax) of $M$ and $t_{\max }$ for teleosts and elasmobranchs combined. Shaded area: $95 \%$ CI. (B) Fit of predicted $M$ estimates from various $t_{\max }$-based indirect estimators (colored lines) compared to the direct $M$ estimates from the adult $M$ database (grey dots) for elasmobranchs (left) and teleosts (right) independently. See Table 1 for details on the different indirect estimators 
Table 4. Sensitivity analysis showing results of different linear regression models used to evaluate if the relationship of natural mortality $\left(M_{i} \log _{\mathrm{e}} \mathrm{Yr}^{-1}\right)$ and maximum age $\left(t_{\max } \log _{\mathrm{e}} \mathrm{yr}\right)$ is $(1)$ different for elasmobranchs and teleosts (linear regression for each taxon individually, linear regression based on comparable maximum ages [direct estimates with $t_{\max } \geq 3$ ]); (2) influenced by a few values (robust regression); or (3) influenced by errors in maximum age (model II major axis regression); $t_{\max }$ was significant ( $<<$ 0.0001) for each model. The Estimator Tmax (base case) with elasmobranchs and teleosts combined is shown in bold

\begin{tabular}{|llll|}
\hline \multirow{2}{*}{ Method } & \multicolumn{2}{c|}{ Model } & \multicolumn{2}{c|}{ Intercept } & Slope \\
\hline Teleosts & & $1.38,1.72$ & $-1.12,-1.00$ \\
Elasmobranch & $\log _{\mathrm{e}}(M)=1.550-1.064 \times \log _{\mathrm{e}}\left(t_{\max }\right)$ & $0.99,2.18$ & $-1.28,-0.89$ \\
Comparable $t_{\text {max }}$ & $\log _{\mathrm{e}}(M)=1.583-1.087 \times \log _{\mathrm{e}}\left(t_{\max }\right)$ & $1.30,1.83$ & $-1.16,-0.98$ \\
Robust regression & $\log _{\mathrm{e}}(M)=1.565-1.071 \times \log _{\mathrm{e}}\left(t_{\max }\right)$ & $1.40,1.71$ & $-1.12,-1.01$ \\
Major axis regression & $\log _{\mathrm{e}}(M)=1.557-1.063 \times \log _{\mathrm{e}}\left(t_{\max }\right)$ & $1.51,1.85$ & $-1.18,-1.06$ \\
Estimator Tmax & $\log _{\mathrm{e}}(M)=1.681-1.115 \times \log _{\mathrm{e}}\left(t_{\max }\right)$ & $\mathbf{1 . 3 9 , \mathbf { 1 . 7 1 }}$ & $\mathbf{- 1 . 1 2}, \mathbf{- 1 . 0 1}$ \\
\hline
\end{tabular}

mator Linf95 estimator and estimated from the life history information in the adult $M$ database for the Estimator Linf. For the latter, the estimated median $X$ was 0.988 , and $X$ did not differ significantly between elasmobranchs and teleosts (Fig. 2A; Wilcoxon $\mathrm{p}=$ 0.54). Hence, the Estimator Linf is given by:

$$
M=\mathrm{e}^{\left\{1.551-1.066 \times \log _{\mathrm{e}}\left[\frac{1}{k} \times \log _{\mathrm{e}}\left(\frac{L_{\infty}-L_{0}}{(1-0.99) \times L_{\infty}}\right)\right]\right\}}
$$

The proportion of individuals in a cohort surviving from birth to $t_{\max }$ (i.e. $P$ ) was also not significantly different between elasmobranchs and teleosts (Fig. 2B; Wilcoxon $p=0.36$ ) and the median percentage of individuals remaining alive at $t_{\max }$ was $1.779 \%$. Therefore, Estimator $P$ is given by:

$$
M=\frac{-\log _{\mathrm{e}}(0.0178)}{t_{\max }}
$$

Estimator Tmax performed best compared to all other tested indirect methods, across elasmobranchs and teleosts (Fig. 3A, Table 5) and among each taxon separately (Fig. S5, Table S4). The previously established indirect adult $M$ estimators tend to overestimate $M$, with average relative errors of up to $100 \%$. From the published indirect adult $M$ estimators, the HoenigFish estimator performed best (Fig. 3A, Table 5). Furthermore, the new Estimator Tmax, Estimator P, and Estimator Linf as well as all estimators from Hoenig (1983) and all estimators based on $P$ had relative errors that were generally smaller than $50 \%$ across all taxonomic orders (Fig. S6), with Estimator Tmax performing generally well (Figs. S6-S8, Table S5).

To test all estimators on a common database, 34 data points were excluded because they were lacking at least one parameter required by any of the adult $M$ estimators. Based on the remaining 86 direct estimates, Estimator Tmax also performed well (Fig. S9,
Table S6). A similar pattern emerged when selecting 10 points randomly from these 86 direct estimates, applying all estimators, calculating the relative error, SMAE, and SMAD, and repeating these steps 1000 times (Fig. S10). The Estimator Tmax predictions also showed the best residual behavior (Fig. S11).

All estimators based on $t_{\max }$ performed better than estimators based on growth except for the Estimator Linf, which also performed better than any other estimator applicable in the absence of observed $t_{\max }$.

\subsection{Juvenile $M$}

In total, 18 directly estimated juvenile $M$ rates were obtained from 16 teleost and 2 elasmobranch populations. Direct estimates included 5 taxonomic orders of 7 families, comprising 8 different teleost and 2 different elasmobranch species. The juvenile direct $M$ rates were estimated primarily from tagging data. Directly estimated $M$ ranged from 3.285 to $0.13 \mathrm{yr}^{-1}$. The mean TL corresponding to the direct juvenile $M$ estimate ranged from 2.8 to $129.1 \mathrm{~cm}, L_{\infty}$ ranged from 18.5 to $398.5 \mathrm{~cm}$, and $L_{m}$ ranged from 11.5 to $232.5 \mathrm{~cm}$, while $k$ ranged from 0.43 to $0.057 \mathrm{yr}^{-1}$. Observed $t_{\max }$ of species in the juvenile $M$ database ranged from 4.5 to 30 yr. For all 18 direct estimates, all life history parameters required by any of the indirect juvenile $M$ estimators were available.

Based on the juvenile $M$ database, the overall best performing estimator was Estimator Lta, $M_{L}=M_{r} \frac{L_{t a}}{L}$, with $M_{r}$ derived from Estimator Tmax and $L_{t a}$ as the reference length (Fig. 3B, Table 5). The Lorenzen (2000) method LorLm - with $M_{r}$ derived from Estimator Tmax but $L_{m}$ as reference length - also performed well (Figs. 3B \& S12, Tables $5 \&$ S7). The residual pat- 



Fig. 2. (A) Percentage of the asymptotic maximum length $\left(L_{\infty} ; \mathrm{cm}\right)$ reached at maximum age ( $t_{\max }$ years). Dashed line: $99 \%$ of $L_{\infty}$ reached at $t_{\text {max }}$ dotted line: $95 \%$. Medians were not significantly different for elasmobranchs and teleosts (Wilcox $\left.\mathrm{p}=0.54\right)$, and the combined median is $99 \%$. (B) Percentage of individuals surviving from birth to maximum age $(P)$. Dashed line: $1 \% P$; dotted line: $5 \% P$. Medians were not significantly different for elasmobranchs and teleosts (Wilcox $\mathrm{p}=0.36$ ) and the combined median is $1.78 \%$. The distribution shape of the data is shown for (A) and (B) around the boxplots - bar: median; box: $25-75 \%$ quantile (interquartile range, IQR); whiskers: max./min. observation $\leq 1.5 x$ IQR above/ below box; dots: outliers

terns of Estimators Lta and LorLm showed roughly constant variability throughout the range of the predicted $M$. However, the Estimator Lta predictions had better residual behavior (Fig. S13). The weight-based estimators all tended to underestimate $M$, while the growth-based estimators tended to overestimate $M$ (Fig. 3B, Table 5). $L_{t a}$ was obtained from $t_{a}$ using the von Bertalanffy growth function. Assuming that $P$ is 0.018 , then it follows from Eq. (17) that $t_{a}=0.5 \times t_{\text {max }}$.

\section{DISCUSSION}

This study investigated if the same indirect approaches to estimate $M$ can be utilized for elasmobranchs and teleosts, or if taxa-specific estimators are required. We found that combined taxa estimators are valid and perform well among and across these 2 taxa. The best-performing indirect adult $M$ estimator, Estimator Tmax, was based on updated data and ordinary linear regression, with $t_{\max }$ as the only covariate. Another updated estimator also performed well, Estimator $P$, where the life history data suggests that in unfished cohorts $P$ is between 1 and $2 \%$ (median: $1.8 \%$ ). In addition, life history data suggest that in the absence of observed $t_{\text {max }}$, this value can be estimated using the von Bertalanffy growth function with the assumption that the length at $t_{\max }$ is at $99 \%$ of $L_{\infty}$. Juvenile $M$ rates were best estimated from a constant adult $M$, by assuming that $M$ is inversely proportional to body length (Lorenzen 2000) and by utilizing a newly introduced reference length, $L_{t a}$. 
Fig. 3. Comparing indirect estimators of natural mortality $(M)$. Shown is the relative error (in percent) in predicting the direct $M\left(\mathrm{yr}^{-1}\right)$ estimate for elasmobranchs and teleosts from the (A) adult and (B) juvenile $M$ database from various indirect estimators. See Table 1 for details on the indirect estimators; boxplot limits as in Fig. 2

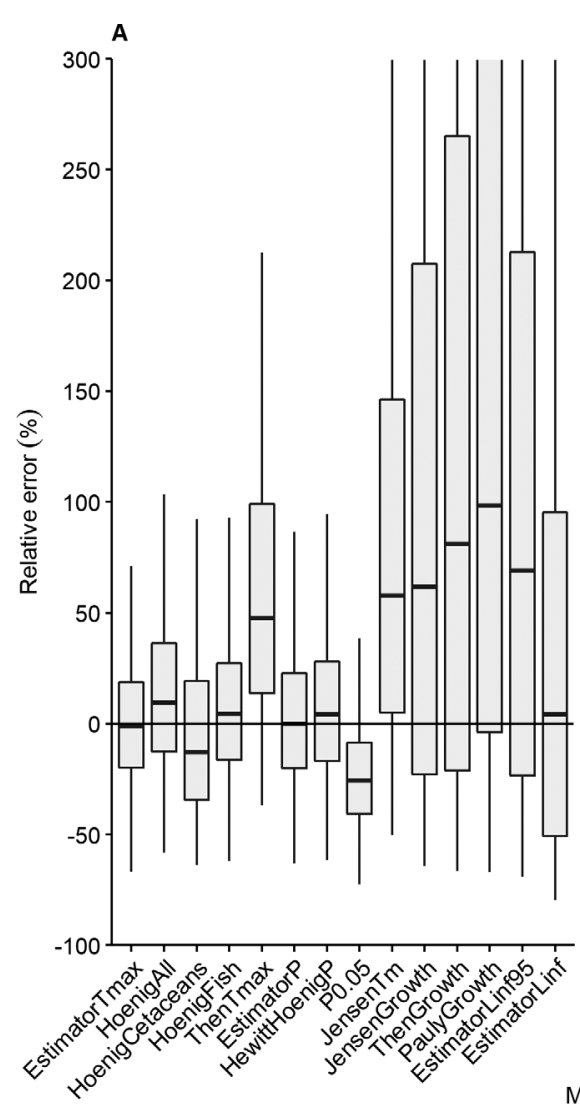

Method

Although the true rate of $M$ is unknown and indirect estimators can only be tested on how well they can reproduce direct $M$ estimates (Then et al. 2015, Hoenig et al. 2016), some approaches presented here appear promising with results highly comparable to direct methods. However, most direct $M$ estimates considered in this study were based on catch curves, and therefore the indirect $M$ estimates are most reflective of estimates from the catch curve method. Hence, the assumptions that apply to the catch curve method should be considered when applying such $M$ estimators; specifically, (1) the sample should be representative of the entire population, with (2) accurate age classes for which the linear function is fitted, and (3) equal vulnerability to the fishing gear, and (4) constant mortality across these age classes, as well as (5) constant mortality and recruitment across years if years were pooled (Simpfendorfer et al. 2005). 
Indirect adult $M$ estimators based on $t_{\max }$ achieved the best overall results in predicting the direct $M$ estimate in the database. This is in accordance with previous studies (Punt et al. 2005, Kenchington 2014, Then et al. 2015). It has also been shown that estimators including information in addition to $t_{\max }$ are not better in predicting $M$ (Then et al. 2015) and, similarly, no improvement was observed here when 'taxa' (elasmobranchs and teleosts) was utilized as an additional covariate.

The exclusion of unreliable $M$ estimates likely explains much of the deviation between the presented estimators here and many previously published and empirically derived estimators (Figs. 3 \& S14). However, this explanation cannot hold for theoretically derived estimators. Jensen's (1996) estimators are based on the ecological theory that species are selected to maximize lifetime fecundity, using Beverton-Holt life history invariants with $M / k=1.5$. However, the $M / k$ ratio has been found to vary considerably among different species (Prince et al. 2015, Thorson et al. 2017), possibly explaining why the 2 indirect $M$ estimators proposed by Jensen (1996) did not perform well across taxa. In addition, the $M / k$ ratio has been reported to differ between some teleost and elasmobranch species (Frisk et al. 2001), whereas no evidence was found here that the relationship between $M$ and $t_{\max }$ differs between these 2 taxa.

The results presented here suggest that for marine fish, similar proportions of individuals are surviving to $t_{\text {max }}$. In the past, arbitrary values of 1 or $5 \%$ have been used for this proportion, while empirical data have suggested $1.5 \%$ (Hewitt \& Hoenig 2005). The empirical data analyzed here suggest a very similar result, with approximately $1-2 \%$ of the individuals surviving from birth to $t_{\max }$. This finding is further supported when examining the survivors from the age at $25 \%$ of $L_{\infty}$ (which might be used as a proxy for the average length when offspring are born; Cortés 2000) to $t_{\max }$ and from $t_{m}$ to $t_{\max }$ (Fig. 4). Approximately $2 \%$ survive from the age at $0.25 L_{\infty}$ to $t_{\max }$ and $5 \%$ from $t_{m}$ to $t_{\text {max }}$ indicating that $P$ is likely smaller than $5 \%$.

In the absence of direct observations, $t_{\max }$ may be estimated in order to predict the $M$ rate. Approaches that estimate $t_{\max }$ solely from maximum length (e.g. Ohsumi 1979) are likely not universal, even within taxa. For example, the oldest known whale is the bowhead whale Balaena mysticetus, reaching ages of more than 200 yr (George et al. 1999); however, it is not the largest whale species. Likewise, the spotted spiny dogfish Squalus suckleyi, a small species of shark, can live for more than 80 yr (Vega et al. 2009).
On the other hand, the von Bertalanffy model utilizes information on growth and has been used previously to estimate $t_{\max }$. This requires an estimate for the proportion of $L_{\infty}$ reached at $t_{\max }$, which has been commonly suggested at $95 \%$ (Taylor 1958, Ricker 1979). The findings here indicate that this value is on average closer to $99 \%$ for marine fish. The estimation of $t_{\text {max }}$ with the von Bertalanffy model also required a value for the length at birth (i.e. $L_{0}$ ), as observed in the wild. However, $t_{\max }$ can also be expressed by applying the concept of half-lives. Fabens (1965) defined $t_{\text {max }}$ as the age reached after 7.22 half-lives, which corresponds to $X=0.9933$, whereas $X=0.95$ (Ricker 1979) corresponds to 4.32 half-lives. In both examples, $L_{0}$ was assumed to be 0 . The number of half-lives will vary according to the value of $L_{0}$ assumed; for example, Cailliet et al. (2006) assumed $L_{0}=0.2 L_{\infty}$ and $X=0.95$, which resulted in a $t_{\max }$ estimate of 4 half-lives. When calculating the half-lives with half-life $=\frac{t_{\max }}{\log _{\mathrm{e}}(2)} \times k$ for each of the 118 observations for which $t_{\text {max }}$ and $k$ were present, the median value across all observations is 5.83 half-lives. This value is between the previously suggested definitions of $t_{\max }$ using the half-life concept, which would be expected given that Fabens (1965) assumed $L_{0}$ to be 0 , which would result in a greater half-life value despite a similar value for $X$ at $\sim 0.99$.

Similar to the findings for adults, this study also suggests that juvenile $M$ can be indirectly estimated using the same estimator for elasmobranchs and teleosts. However, the results should be viewed with caution, given the small sample size and uncertainty associated with the data. For example, the mean TL at the direct $M$ estimate was only given for 3 data points, and for one of these 3 data points, only fork length was given so TL had to be approximated. In most cases, the mean TL was estimated from age using the von Bertalanffy growth function rather than being directly observed in the study. Nevertheless, the presented Estimator Lta performed generally well in predicting juvenile $M$, with more accurate predictions than any other previously published age-, size-, or weight-dependent indirect estimator. The Estimator Lta utilized a newly introduced reference length, $L_{t a}$. This length was generally larger than $L_{m}$, with the median ratio $L_{t a} / L_{m}=1.25$ (range: $0.91-$ 1.89), while the ratio with $L_{\infty}, L_{t a} / L_{\infty}=0.72$ (range: 0.48-0.92), for all 18 direct estimates. This indicates that $L_{t a}$ is typically larger than $L_{m}$ (Fig. S15), and therefore $L_{t a}$ might be more closely associated with the length at which all individuals are mature, $L_{m 100}$. The corresponding value of $t_{a}$ was found to occur at 
A

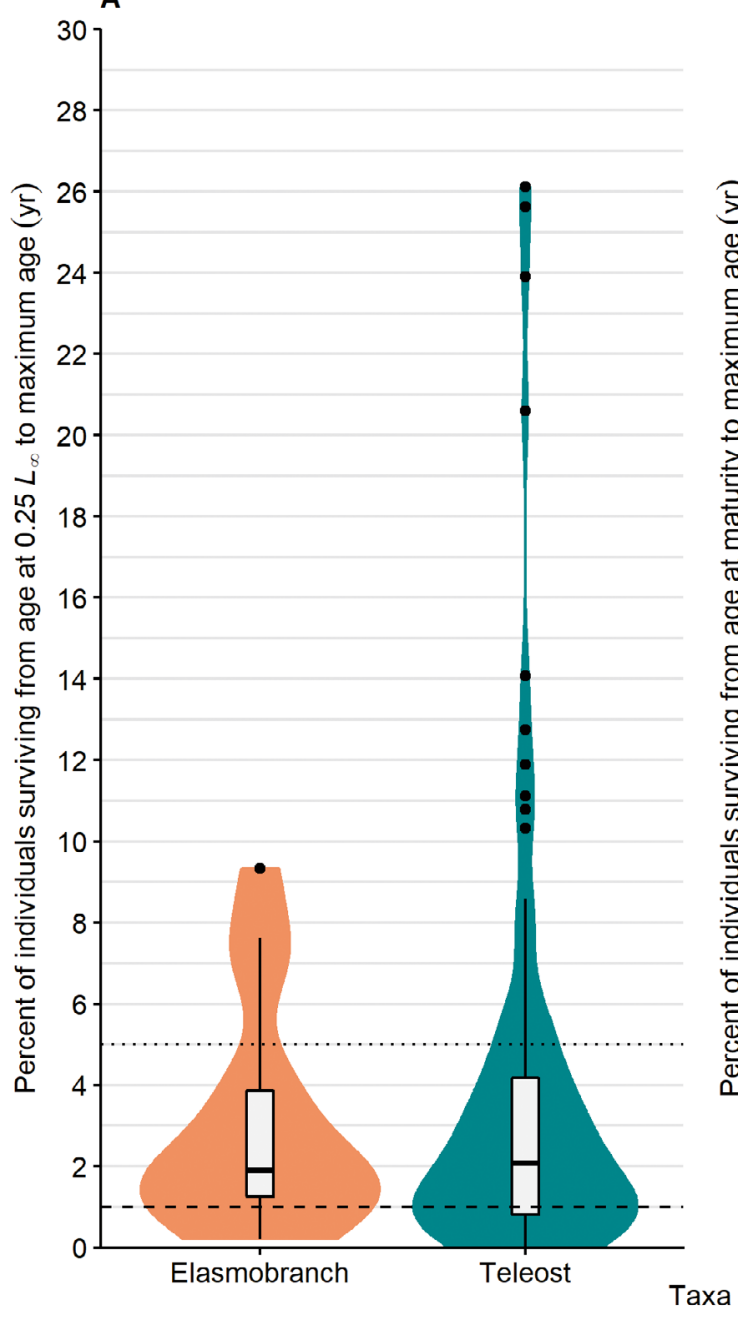

B

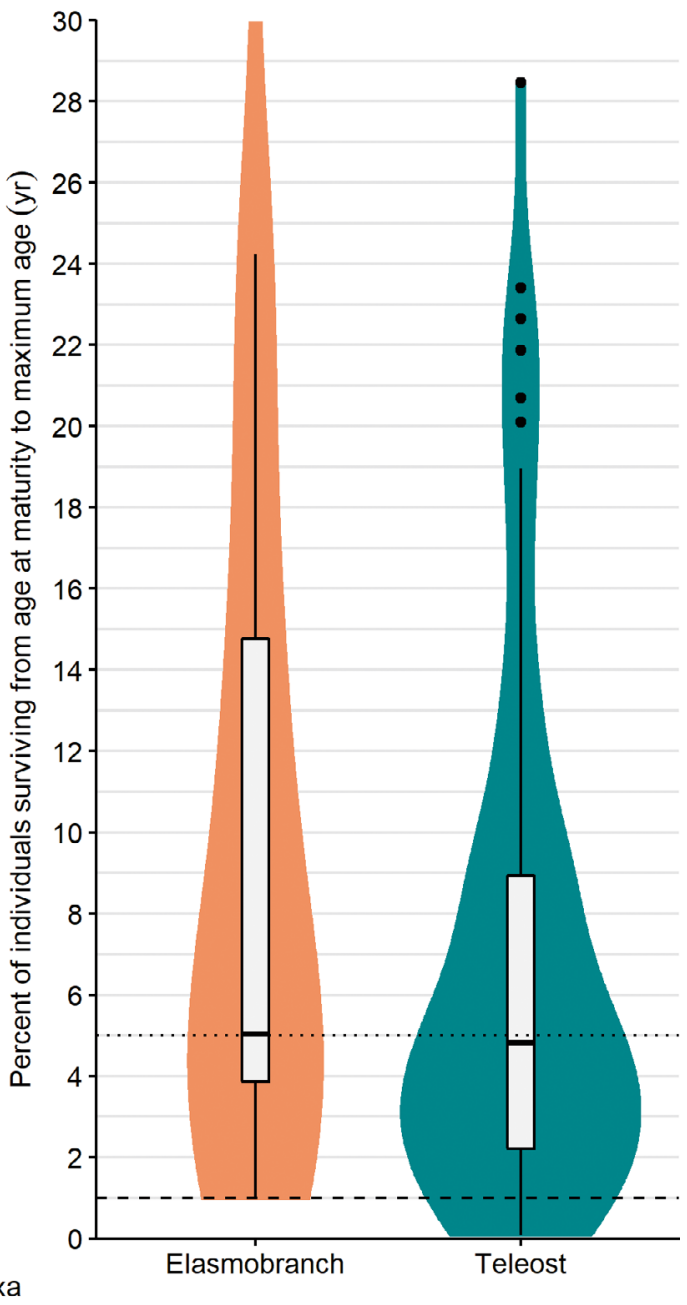

Fig. 4. Percentage of individual teleosts and elasmobranchs surviving from (A) the age at $25 \%$ of the asymptotic maximum length $\left(L_{\infty}\right)$ to maximum age $\left(t_{\max }\right)$ and (B) age at maturity, $t_{m}$, to $t_{\max }$. Dashed line: $1 \%$ of individuals surviving; dotted line: $5 \%$ survivors. The distribution shape of the data is shown for (A) and (B) around the boxplots (boxplot limits as in Fig. 2)

$\sim 0.5 t_{\text {max }}$, whereas $t_{m}$ generally occurs at $0.16-0.5 t_{\text {max }}$ (Beverton 1992, Cortés 2000, Frisk et al. 2001), indicating $t_{m} \leq t_{a}$.

In conclusion, taxon-specific indirect $M$ estimators are not required for teleosts and elasmobranchs when based on $t_{\text {max }}$. Such a universal $M$ estimator has been suggested by Hoenig (1983) for molluscs, fish, and cetaceans combined. Hoenig's (1983) reasoning for a combined taxa estimator, instead of using one estimator for each of the taxa, was to use the model with the widest range of $t_{\max }$ and the highest coefficient of determination. In addition, we found that a combined taxa estimator for teleosts and elasmobranchs can likely be explained by the similar value of $P$ in an unfished cohort (Fig. 2B), which then suggests the same relationship between $t_{\max }$ and $M$ when the numbers in a cohort decay exponentially (Eqs. 1 \& 8). Therefore, a relatively simple, reliable, and general approach can be utilized for elasmobranchs and teleosts in data-poor situations when estimating adult $M$ rates from $t_{\text {max }}$. Although there is strong evidence that $M$ declines with increased individual length (Peterson \& Wroblewski 1984, Chen \& Watanabe 1989, Lorenzen 1996, 2000, Gislason et al. 2010), a constant $M$ for mature individuals might still be appropriate (Brodziak et al. 2011, Deroba \& Schueller 2013, Johnson et al. 2015). The stress of reproduction and other intrinsic factors, such as the accumulation of harmful mutations, may cause $M$ to increase at larger sizes or older ages (actuarial senescence); however, this phenomenon is currently not easily predictable (Brodziak et al. 2011), and actuarial senescence was not examined in this study. It has been previously suggested that $M$ follows the Lorenzen curve up to $L_{m}$ and is constant thereafter. This suggestion is based on the assump- 
tion that an increase in mortality after reproduction is compensated by a decrease in mortality due to larger size (Brodziak et al. 2011). The results presented here suggest that size-dependent $M$ for juveniles can be approximated using the adult constant $M$ (Lorenzen 2000), albeit the small sample size warrants future validation. In its minimal form, the Estimator Linf allows size-dependent $M$ to be estimated from growth information alone by using $t_{\max }=\frac{1}{k} \times \log _{\mathrm{e}}\left(\frac{L_{\infty}-L_{0}}{(1-0.99) \times L_{\infty}}\right)$ and assuming that $P$ is between 1 and $2 \%$. The results of this study, combined with recent advances in estimating growth (Dureuil 2019), could thus allow for relatively wide applicability in data-poor situations. More generally, the estimators could be used to indirectly estimate an $M$ rate for stock assessment purposes or to obtain informative priors in Bayesian analyses. Also, $M$ can play an important role when estimating pre-disturbance generation length (a critical measure to assess population reduction), to evaluate extinction risk on the IUCN Red List of Threatened Species (IUCN 2019), and in rebuilding plans (Patrick \& Cope 2014). The presented estimators may also be applicable for species other than marine fish if there is reason to believe that mortality curves and $P$ are similar across disparate taxa or species, such as in freshwater fish, cetaceans, and invertebrates (Hoenig 1983, Hewitt et al. 2007, McCoy 2008, Maceina \& Sammons 2016). The application of indirect estimators should, however, also consider some form of sensitivity analysis, given the importance of an accurate and precise $M$ estimate and the difficulties in estimating $M$. For example, the von Bertalanffy growth function and information from similar species could be used to determine if the observed $t_{\max }$ growth, and the estimated $M$ rate are biologically reasonable. Furthermore, it should be recognized that the $M$ estimate pertains to the time period for which life history parameters were derived, and that $M$ can change over time (Deroba \& Schueller 2013) and with exploitation pressure (Jørgensen \& Fiksen 2010). In addition, Estimator $P$ is also less biased than Estimator Tmax when $t_{\max }$ is highly underestimated (Fig. S16), which can be of particular interest in elasmobranch species with age underestimation (Harry 2018). Such considerations are highly relevant, given the complex relationships of $M$ to life history data and various properties relevant to fisheries management (Fig. 5). It is hoped that the updated estimators presented here will enhance the estimation of $M$ and thus fisheries assessments in data-poor situations, allowing for more species to be assessed and managed based on minimal data.



Fig. 5. Estimation of natural mortality $(M)$ in data-poor and data-rich stocks. Different direct and indirect methods to estimate $M$ are indicated along with their main data requirements. Generally, information on the population structure or emigration rate is required across methods. The heavier-weighted line indicates that a direct approach should be preferred when required data is available. The lower 4 boxes give examples of properties relevant for assessment and fisheries management that require an estimate of $M$ (bold type for emphasis) 
Acknowledgements. We thank Drs. Rainer Froese, Michael Dowd, Chris Harvey-Clark, Frederick G. Whoriskey, and Neil Hammerschlag for comments and feedback which helped improve the manuscript. We are grateful to Rory McAuley for providing sandbar shark tagging data and Bryan Frazier for providing information on bonnethead growth and very helpful feedback and comments. All authors also gratefully acknowledge the open data policy from previous authors working on this topic and the Information and Data Centre at Commonwealth Scientific and Industrial Research Organisation (CSIRO) Oceans and Atmosphere, Australia. Research funding was provided by the Ocean Frontier Institute through an award from the Canada First Research Excellence Fund.

\section{LITERATURE CITED}

Beverton RJH (1992) Patterns of reproductive strategy parameters in some marine teleost fishes. J Fish Biol 41: $137-160$

Beyer JE, Kirchner CH, Holtzhausen JA (1999) A method to determine size-specific natural mortality applied to westcoast steenbras (Lithognathus aureti) in Namibia. Fish Res 41:133-153

Brodziak J, Ianelli J, Lorenzen K, Methot RD Jr (2011) Estimating natural mortality in stock assessment applications. NOAA Tech Memo NMFS-F/SPO 119

Cadima EL (2003) Fish stock assessment manual. FAO Fish Tech Pap 393:1-161

Cailliet GM, Goldman KJ (2004) Age determination and validation in chondrichthyan fishes. In: Wetherbee BM, Cortés E, Carrier JC, Musick JA, Heithaus MR (eds) Biology of sharks and their relatives. CRC Press, Boca Raton, FL, p 399-447

Cailliet GM, Smith WD, Mollet HF, Goldman KJ (2006) Age and growth studies of chondrichthyan fishes: the need for consistency in terminology, verification, validation, and growth function fitting. Environ Biol Fishes 77:211-228

Camhi M, Fowler S, Musick J, Bräutigam A, Fordham S (1998) Sharks and their relatives - ecology and conservation. IUCN/SSC Shark Specialist Group, Gland

Charnov EL, Gislason H, Pope JG (2013) Evolutionary assembly rules for fish life histories. Fish Fish 14:213-224

Cheilari A, Rätz HJ (2009) The effect of natural mortality on the estimation of stock state parameters and derived references for sustainable fisheries management. ICES CM 2009/N:03

Chen S, Watanabe S (1989) Age dependence of natural mortality coefficient in fish population dynamics. Bull Jpn Soc Sci Fish 55:205-208

* Clark WG (1999) Effects of an erroneous natural mortality rate on a simple age-structured stock assessment. Can J Fish Aquat Sci 56:1721-1731

* Cortés E (1998) Demographic analysis as an aid in shark stock assessment and management. Fish Res 39:199-208

Cortés E (2000) Life history patterns and correlations in sharks. Rev Fish Sci 8:299-344

Cortés E (2002) Incorporating uncertainty into demographic modeling: application to shark populations and their conservation. Conserv Biol 16:1048-1062

Costello C, Ovando D, Clavelle T, Strauss CK and others (2016) Global fishery prospects under contrasting management regimes. Proc Natl Acad Sci USA 113:5125-5129

Deroba JJ, Schueller AM (2013) Performance of stock as- sessments with misspecified age- and time-varying natural mortality. Fish Res 146:27-40

* Dulvy NK, Fowler SL, Musick JA, Cavanagh RD and others (2014) Extinction risk and conservation of the world's sharks and rays. Elife 3:e00590

Dureuil M (2019) Evaluating vital components of elasmobranch assessment and spatial conservation. PhD dissertation, Dalhousie University, Halifax

Fabens AJ (1965) Properties and fitting of the von Bertalanffy growth curve. Growth 29:265-289

Frisk MG, Miller TJ, Fogarty MJ (2001) Estimation and analysis of biological parameters in elasmobranch fishes: a comparative life history study. Can J Fish Aquat Sci 58: 969-981

* Froese R (2006) Cube law, condition factor and weightlength relationships: history, meta-analysis and recommendations. J Appl Ichthyology 22:241-253

Froese R, Pauly D (eds) (2019) FishBase. www.fishbase.org (accessed 6 February 2018)

*George JC, Bada J, Zeh J, Scott L, Brown SE, O'Hara T, Suydam R (1999) Age and growth estimates of bowhead whales (Balaena mysticetus) via aspartic acid racemization. Can J Zool 77:571-580

Gislason H, Daan N, Rice JC, Pope JG (2010) Size, growth, temperature and the natural mortality of marine fish. Fish Fish 11:149-158

* Gruber SH, De Marignac JR, Hoenig JM (2001) Survival of juvenile lemon sharks at Bimini, Bahamas, estimated by mark-depletion experiments. Trans Am Fish Soc 130: 376-384

Gulland JA (1971) The fish resources of the ocean. Fishing News (Books), West Byfleet

Haddon M (2011) Modelling and quantitative methods in fisheries, $2^{\text {nd }}$ edn. Chapman and Hall/CRS Press, Boca Raton, FL

* Harry AV (2018) Evidence for systemic age underestimation in shark and ray ageing studies. Fish Fish 19:185-200

* Heupel MR, Simpfendorfer CA $(2002)$ Estimation of mortality of juvenile blacktip sharks, Carcharhinus limbatus, within a nursery area using telemetry data. Can J Fish Aquat Sci 59:624-632

*Heupel MR, Simpfendorfer CA (2011) Estuarine nursery areas provide a low-mortality environment for young bull sharks Carcharhinus leucas. Mar Ecol Prog Ser 433:237-244

Hewitt DA, Hoenig JM (2005) Comparison of two approaches for estimating natural mortality based on longevity. Fish Bull 103:433-437

K Hewitt DA, Lambert DM, Hoenig JM, Lipcius RN, Bunnel DB, Miller TJ (2007) Direct and indirect estimates of natural mortality for Chesapeake Bay blue crab. Trans Am Fish Soc 136:1030-1040

KHisano M, Connolly SR, Robbins WD (2011) Population growth rates of reef sharks with and without fishing on the Great Barrier Reef: robust estimation with multiple models. PLOS ONE 6:e25028

Hoenig J (1983) Empirical use of longevity data to estimate mortality rates. Fish Bull 82:898-903

Hoenig JM, Gruber SH (1990) Life-history patterns in the elasmobranchs: implications for fisheries management. NOAA Tech Rep NMFS 90

* Hoenig JM, Barrowman NJ, Hearn WS, Pollock KH (1998) Multiyear tagging studies incorporating fishing effort data. Can J Fish Aquat Sci 55:1466-1476

*Hoenig JM, Then AYH, Babcock EA, Hall NG, Hewitt DA, Hesp SA (2016) The logic of comparative life history 
studies for estimating key parameters, with a focus on natural mortality rate. ICES J Mar Sci 73:2453-2467

IUCN (2019) Guidelines for using the IUCN Red List categories and criteria, version 14. www.iucnredlist.org/ documents/RedListGuidelines.pdf (accessed 27 May 2020)

Jensen AL (1996) Beverton and Holt life history invariants result from optimal trade-off of reproduction and survival. Can J Fish Aquat Sci 53:820-822

Johnson KF, Monnahan CC, McGilliard CR, Vert-pre KA and others (2015) Time-varying natural mortality in fisheries stock assessment models: identifying a default approach. ICES J Mar Sci 72:137-150

* Jørgensen C, Fiksen $\varnothing$ (2010) Modelling fishing-induced adaptations and consequences for natural mortality. Can J Fish Aquat Sci 67:1086-1097

Kenchington TJ (2014) Natural mortality estimators for information-limited fisheries. Fish Fish 15:533-562

Kindsvater HK, Dulvy NK, Horswill C, Juan-Jorda MJ, Mangel M, Matthiopoulos J (2018) Overcoming the data crisis in biodiversity conservation. Trends Ecol Evol 33: 676-688

Knip DM, Heupel MR, Simpfendorfer CA (2012) Mortality rates for two shark species occupying a shared coastal environment. Fish Res 125-126:184-189

Lee H, Maunder MN, Piner KR, Methot RD (2011) Estimating natural mortality within a fisheries stock assessment model: an evaluation using simulation analysis based on twelve stock assessments. Fish Res 109:89-94

Legendre P (2018) lmodel2: model II regression. R package version 1.7-3. https://CRAN.R-project.org/package= lmodel2

Lessa R, Batista VS, Santana FM (2016) Close to extinction? The collapse of the endemic daggernose shark (Isogomphodon oxyrhynchus) off Brazil. Glob Ecol Conserv 7: 70-81

* Liu KM, Chin CP, Chen CH, Chang JH (2015) Estimating finite rate of population increase for sharks based on vital parameters. PLOS ONE 10:e0143008

* Lorenzen K (1996) The relationship between body weight and natural mortality in juvenile and adult fish: a comparison of natural ecosystems and aquaculture. J Fish Biol 49:627-647

LLorenzen K (2000) Allometry of natural mortality as a basis for assessing optimal release size in fish-stocking programmes. Can J Fish Aquat Sci 57:2374-2381

Maceina MJ, Sammons SM (2016) Assessing the accuracy of published natural mortality estimators using rates determined from five unexploited freshwater fish populations. N Am J Fish Manage 36:433-446

Maindonald JH, Braun JW (2015) DAAG: data analysis and graphics data and functions. R package version 1.22. https://CRAN.R-project.org/package=DAAG

Maunder MN, Wong RA (2011) Approaches for estimating natural mortality: application to summer flounder (Paralichthys dentatus) in the U.S. mid-Atlantic. Fish Res 111:92-99

McAuley RB, Simpfendorfer CA, Hall NG (2007) A method for evaluating the impacts of fishing mortality and stochastic influences on the demography of two long-lived shark stocks. ICES J Mar Sci 64:1710-1722

McCoy MW (2008) Predicting natural mortality rates of plants and animals. Ecol Lett 11:710-716

Nielsen J, Steffensen JF, Christiansen JS, Heinemeier J and others (2016) Eye lens radiocarbon reveals centuries of longevity in the Greenland shark (Somniosus microcephalus). Science 353:702-704

Ohsumi S (1979) Interspecies relationships among some biological parameters in cetaceans and estimation of the natural mortality coefficient of the Southern Hemisphere minke whale. Rep Int Whaling Comm 29:397-406

*Pardo SA, Cooper AB, Reynolds JD, Dulvy NK (2018) Quantifying the known unknowns: Estimating maximum intrinsic rate of population increase in the face of uncertainty. ICES J Mar Sci 75:953-963

Patrick WS, Cope J (2014) Examining the 10-year rebuilding dilemma for US Fish stocks. PLOS ONE 9:e112232

*Pauly D (1980) On the interrelationships between natural mortality, growth parameters, and mean environmental temperature in 175 fish stocks. ICES J Mar Sci 39:175-192

Pauly D (1984) Fish population dynamics in tropical waters: a manual for use with programmable calculators. WorldFish, International Center for Aquatic Living Resources Management, Manila

*Peterson I, Wroblewski S (1984) Mortality rate of fishes in the pelagic ecosystem. Can J Fish Aquat Sci 41:1117-1120

* Prince J, Hordyk A, Valencia SR, Loneragan N, Sainsbury K (2015) Revisiting the concept of Beverton-Holt life-history invariants with the aim of informing data-poor fisheries assessment. ICES J Mar Sci 72:194-203

Punt A, Smith DC, Koopman MT (2005) Using information for 'data-rich' species to inform assessments of 'datapoor' species through Bayesian stock assessment methods. Project No. 2002/094. Final report to Fisheries Research and Development Corporation. Primary Industries Research Victoria, Queenscliff

* Queiroz N, Humphries NE, Couto A, Vedor M and others (2019) Global spatial risk assessment of sharks under the footprint of fisheries. Nature 572:461-466

R Core Team (2018) R: a language and environment for statistical computing. R Foundation for Statistical Computing, Vienna

Kicker WE (1979) Growth rates and models. In: Hoar WS, Randall DJ, Brett JR (eds) Fish physiology, Vol 8. Academic Press, New York, NY, p 677-743

Simpfendorfer CA (1999) Mortality estimates and demographic analysis for the Australian sharpnose shark, Rhizoprionodon taylori, from northern Australia. Fish Bull 97:978-986

Simpfendorfer CA (2005) Demographic models: life tables, matrix models and rebound potential. FAO Fish Tech Pap 474:143-153

* Simpfendorfer CA, Dulvy NK (2017) Bright spots of sustainable shark fishing. Curr Biol 27:R97-R98

Simpfendorfer CA, Bonfil R, Latour RJ (2005) Mortality estimation. FAO Fish Tech Pap 474:127-142

* Sims SE (1984) An analysis of the effect of errors in the natural mortality rate on stock-size estimates using virtual population analysis (cohort analysis). ICES J Mar Sci 41: 149-153

* Smith SE, Au DW, Show C (1998) Intrinsic rebound potentials of 26 species of Pacific sharks. Mar Freshw Res 49: $663-678$

* Taylor CC (1958) Cod growth and temperature. ICES J Mar Sci 23:366-370

* Then AY, Hoenig JM, Hall NG, Hewitt DA (2015) Evaluating the predictive performance of empirical estimators of natural mortality rate using information on over 200 fish species. ICES J Mar Sci 72:82-92

Thorson JT, Munch SB, Cope JM, Gao J (2017) Predicting 
life history parameters for all fishes worldwide. Ecol Appl 27:2262-2276

Vega NM, Gallucci VF, Hauser L, Franks J (2009) Differences in growth in the spiny dogfish over a latitudinal gradient in the Northeast Pacific. In: Gallucci VF, McFarlane GA, Bargmann G (eds) Biology and management of dogfish sharks. American Fisheries Society, Bethesda, MD, p 169-180

Venables WN, Ripley BD (2002) Modern applied statistics with S, $4^{\text {th }}$ edn. Springer, New York, NY

Vetter EF (1988) Estimation of natural mortality in fish stocks: a review. Fish Bull 86:25-43

von Bertalanffy L (1938) A quantitative theory of organic

Editorial responsibility: Myron Peck,

Den Burg, The Netherlands

Reviewed by: Jane Dankel and 2 anonymous referees growth (inquiries on growth laws. II). Hum Biol 10: 181-213

WWalther BA, Moore JL (2005) The concepts of bias, precision and accuracy, and their use in testing the performance of species richness estimators, with a literature review of estimator performance. Ecography 28:815-829

* Yokoi H, Ijima H, Ohshimo S, Yokawa K (2017) Impact of biology knowledge on the conservation and management of large pelagic sharks. Sci Rep 7:10619

Zhou S, Yin S, Thorson JT, Smith ADM, Fuller M (2012) Linking fishing mortality reference points to life history traits: an empirical study. Can J Fish Aquat Sci 69: 1292-1301

Submitted: June 25, 2020

Accepted: March 22, 2021

Proofs received from author(s): May 23, 2021 